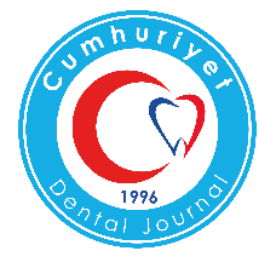

\title{
REMOVAL OF SEPARATED INSTRUMENTS WITH MASSERANN TECHNIQUES: TWO CASE REPORTS
}

Masserann Tekniği ile Kırık Aletlerin Uzaklaştırılması: İki Olgu Sunumu

Hakan GÖKTÜRK, İsmail ÖZKOÇAK

\begin{tabular}{ll} 
Makale Kodu/Article Code & $: 205221$ \\
Makale Gönderilme Tarihi & $: 23.10 .2016$ \\
Kabul Tarihi & $: 13.01 .2017$ \\
\hline
\end{tabular}

ABSTRACT

Instrument fracture is a procedural mishap that prevents efficient cleaning and shaping of the root canal. When bypassing the fracture fails, the fragment must be removed. Many techniques and devices have been described to remove fragments from the root canal. The Masserann Kit is a widely used instrument for the removal of fragments. These clinical cases describe use of the Masserann Kit to remove separated instruments blocking the entire canal in posterior teeth.

Keywords: Endodontics, Instrument removal, Masserann Kit, Seperated file

\section{ÖZ}

Enstrüman kırı̆̆ı, kök kanalının etkin şekilde temizlenmesini ve şekillenmesini önleyen bir prosedür hatasıdır. Kırık parçayı atlayarak yanından geçilmesi (bypass) başarısız olduğunda, parça çıkarılmalıdır. Kırık parçanın kök kanalından uzaklaştırılması için birçok teknik ve cihaz geliştirilmiştir. Masserann Kit, kırık parçaların çıkarılması için yaygın olarak kullanılan bir alettir. Bu klinik olgularda, arka bölgedeki dişlerde tüm kanalı tıkayan kırık parçaları uzaklaştırmak için Masserann Kit kullanımını sunulmuştur.

Anahtar Kelimeler: Endodonti, Alet uzaklaştırma, Masserann Kiti, Kırık eğe 


\section{INTRODUCTION}

Instrument breakage is an undesirable situation that may arise during root canal preparation. Breakage of an instrument jeopardizes the proper preparation and obturation of the entire root canal system. ${ }^{1}$ Nowadays, the use of nickel-titanium (NiTi) rotary files for root canal preparation is more common than stainless steel files. For this reason, the incidence of NiTi rotary files separation is more than stainless files. ${ }^{2,}{ }^{3} \mathrm{NiTi}$ instruments are exposed to excessive torsional or flexural fatigue (cyclic fatigue) and will fracture without showing visible signs of breakage. ${ }^{4}$ The clinician should be prepared for unexpected complications during endodontic treatment.

When instrument breakage occurs, the fragment can be removed or bypassed and sealed within the root canal space or true blockage can be performed., 5 Certainly removal of the fractured instruments is the best treatment option. However the removal of separated instruments from the root canal is impossible or very difficult in many cases and can also be very time consuming. Furthermore, the success rate of instrument removal procedures ranges from 47.6-95.2\%. ${ }^{1,6,7}$ The removal of an instrument fragment is influenced by the anatomy of the root canal, the length of the separated fragment, and the remaining tooth structure. ${ }^{1,5,7-9} \mathrm{~A}$ variety of devices and techniques to remove fractured instruments have been described, including drills, extractors, ultrasonic tips, dental operating microscopes, and electrochemical processes. $^{5}, 8,10,11$ These techniques have shown encouraging results. However no standard protocol for the removal of separated instrument is currently available. ${ }^{1}$

The Masserann Kit (Micro-Mega, Besancon, France) is a widely used instrument for the removal of separated instruments. ${ }^{1,1-13}$ It consist of a series of color coded trepan burs (diameter ranging from 1.1 to $2.4 \mathrm{~mm}$ ), two size extractors $(1.2$ and $1.5 \mathrm{~mm}$ in outer diameter) and other accessories. ${ }^{14}$ A staging platform and canal should be prepared at the coronal part of the fragment using Gates Glidden drills. The trepan burs are rotated counter-clockwise to cut the dentin around the coronal end of the fragment and create a suitable space for the extractor tubes. An extractor with a plunger rod (stylet) is used to grip and dislodge the fragment. This technique is used in straight canal portions. The use of this technique in the thin and curvature canal is dangerous.

The aim of this presentation is to describe the removal of broken instruments that block the entire root canal using the Masserann Kit.

\section{CASES PRESENTATION}

Case 1: 44-year-old male patient was referred to the Department of Endodontics for root canal treatment of tooth number \#14 (maxillary right first premolar) by his general dentist. Clinical examination revealed gross and deep occlusal caries in tooth \#14. The tooth was asymptomatic upon palpation and percussion. Radiographic examination revealed curved and narrow canals associated with periapical lesion (Figure 1a). The tooth elicited a negative response on thermal and electric pulp tests. A diagnosis of pulp necrosis with chronic apical periodontitis was made and root canal treatment was suggested for tooth \#14. After isolation of the tooth with a rubber dam, the access cavity was prepared. During root canal preparation $8 \mathrm{~mm}$ of a $15 \mathrm{~K}$-file was separated in the palatal canal. Radiographic examination confirmed that the entire length of the palatal canal was blocked by the separated instrument with a small portion of the file extending beyond the apex (Figure 1b). The patient was informed of this accidental event and about the treatment options to remove the separated part of the instrument. It was decided to use the Masserann technique. A modified 3 Gatess Glidden drill (Dentsply Maillefer, Ballaigues, Switzerland) was used to create direct access 
to the fragment and a straight platform. Three trepan burs (1, 2 and 3, respectively) were subsequently used to remove the surrounding dentin using a handpiece at $300 \mathrm{rpm}$ in a counter-clockwise rotation. The fragment was not removed during trephining. A small extractor tube with a diameter of $1.2 \mathrm{~mm}$ was used to grip the broken instrument. An extractor tube gripping the fragment was gently rotated in a counter-clockwise direction to retrieve the fragment. A radiograph was taken to confirm instrument removal (Figure 1c). Preparation of all canals was completed using a ProTaper Universal system with full sequence up to F3 (PTU; Dentsply Tulsa Dental, Tulsa, OK). The root canals were copiously irrigated with $2.5 \%$ sodium hypochlorite (Whitedentmed, Erhan Kimya, İzmir, Turkey) and 17\% ethylenediaminetetraacetic acid (Imicryl Ltd., Konya, Turkey) during the preparation. The root canals were filled with epoxy-amine resinbased sealer (2Seal, VDW, Munich, Germany) and gutta-percha points (Dentsply Maillefer, Tulsa, OK) using the cold lateral condensation technique. The tooth was provisionally sealed with temporary filling material (Cavit G $3 \mathrm{M}$ Espe, Seefeld, Germany). Two days later a screw post (Nordin Screw Posts, H. Nordin SA, Swiss) placed in the palatal root canal and the access cavity was restored with composite resin (3M Filtek Z-250, 3M ESPE, St. Paul, MN, USA) (Figure 1d). The patient was then referred to the prosthodontics clinic for a full crown restoration. At the 6 month follow up visit the tooth was asymptomatic without any radiographic changes (Figure 1e). For this reason, it was decided to follow the teeth radiographically at intervals of six months. However the tooth was not restored with a crown and the patient was redirected to the prosthodontics clinic.

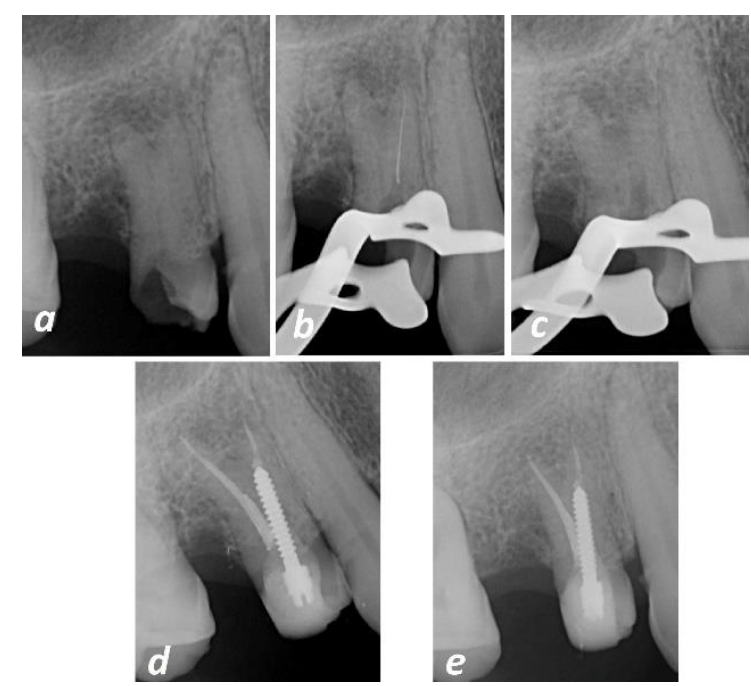

Figure 1. (a) A pre-operative radiograph of Case 1. (b) Broken instrument (15 K-file) in the entire palatal canal of maxillary right first premolar. (c) A radiograph confirmed the removal of broken instrument. (d) A post-operative radiograph showing the obturation and restoration. (e) Six month follow-up.

Case 2: A 44-year-old male patient was referred to our clinic with complaints of pain and swelling in the maxillary right region. Clinically, tooth \#16 and \#17 had porcelainfused-to-metal crowns and were tender to percussion. Radiographic examination revealed that tooth \#17 had a deep restoration under the prosthesis and a wide radiolucent area in the apical region (Figure 2a). After the removal of prosthesis, an electric pulp test and cold application were applied to tooth \#17 and there was no response these vitality tests. The tooth was diagnosed with chronic apical periodontitis. After isolation with a rubber dam, the access cavity was prepared. During root canal preparation a ProTaper Universal S1 (Dentsply, OK) file was fractured in the mesiobuccal canal. Radiographic examination revealed that the fragment was occupying the entire length of the canal (Figure 2b). Clinically, the broken fragment did not extend to the pulp chamber. The fragment could not be grasped coronally and it was decided to use the Masserann technique. Three trepan burs (2, 3 , and 4 , respectively) were used to create space between the fragment and the root canal wall. The small extractor tube was used to grip the fragment. The tube with the locked fragment was gently rotated in a counterclockwise direction to retrieve the fragment. A 
radiograph was taken to confirm removal of the broken file (Figure 2c). The root canals were obturated as described previously in case 1 without intracanal post placement (Figure $2 \mathrm{~d}$ ). The tooth was restored with porcelain fused to a metal crown. At the six-month follow-up the tooth was asymptomatic and there was reduced periapical radiolucency (Figure 2e).

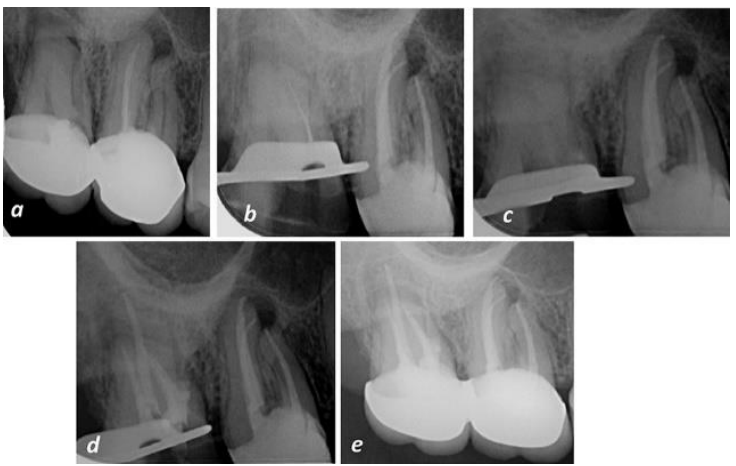

Figure 2. (a) A pre-operative radiograph of Case 2. (b) Broken instrument (ProTaper Universal S1) in the entire mesio-buccal canal of maxillary right second molar. (c) A radiograph confirmed retrieval of the fragment. (d) Final restoration and obturation. (e) Six month follow-up.

\section{DISCUSSION}

Breakage of an endodontic instrument during root canal preparation impedes thorough cleaning and shaping of the root canal and prevents access to the apex. Breakage also reduces the likelihood of endodontic treatment success. ${ }^{1}$

When an instrument is broken in the root canal, clinicians need to make a decision on extraction, surgery, instrument removal or continued endodontic treatment. Clinicians should consider that the type and condition of the tooth (vital or non-vital), accessibility, and position of the fractured instrument in the canal, the type of pulpal pathology, the degree of cleaning and shaping at the time of separation, periapical pathosis and skill and experience of the clinician. ${ }^{1,3,6,8}$ Orthograde retrieval is a time consuming and often a difficult procedure. Many orthograde techniques such as grasping with hemostats, a tube and Hedstrom file, wire loops, and devices such as the Masserann Kit, Instrument Removal System (IRS), Endo Extractor, Endo Safety System, and ultrasonics have been described for fragment retrieval. ${ }^{1,3,5,7,11-13}$

The Masserann Kit is a useful device for the removal of broken instruments, especially in cases where fragments are in a readily accessible position and tightly wedged. The Masserann Kit is designed for removing metallic objects from straight rooted anterior teeth. However it has limited application in curved rooted posterior teeth. Long and rigid trepan burs and extractors preclude the use of the Masserann Kit within the limited access of the canal. These instruments remove excess dentine, weaken the root, and can predispose to root fracture or perforation. ${ }^{4,12}$

In present study, the Masserann technique was employed when attempts to grasp the fragment with a hemostat failed. Despite positioning of the teeth in the posterior and the presence of a moderately curved canal, the Masserann technique was used successfully. The level of the fractured instrument allowed for minimal dentin removal around the peripheral dentin surrounding the fragment. The exposed coronal end of the fragment was accessible to locking and gripping by the extractor. The small extractor tube with the locked fragment was rotated in a counterclockwise direction to remove fragments.

Ultrasonics is considered to be superior to Masserann Kit for fragment removal. ${ }^{1}$ However, NiTi instruments usually break under ultrasonic vibration due to heat buildup. ${ }^{15}$ In addition, ultrasonic and Masserann techniques result in similar weakening of straight roots. ${ }^{5}$ The Masserann Kit was used in these cases due to blockage of the entire length of the canal with coronal access.

The retrieval of broken instruments is sometimes a time consuming and difficult procedure. The literature reports a success rate of $47.6-95.2 \% .^{1,6,7}$ 
Previous studies have shown that the success rate of these procedures increases when the fragment is visible using an operating microscope. ${ }^{6,8,10}$ The probability of fragment retrieval is reduced when the canal curvature angle is increased. ${ }^{1,7}$ Excessive dentine removal creates straight-line access within the curved canal. This leads to weakening of the tooth and perforation. Ideally, dentin removal should be reduced as much as possible while creating access to the fragment. In the present cases, the coronal level of the fragment was near the orifice of the canal and minimal dentin removal was created to expose at least $1.5 \mathrm{~mm}$ of the fragment in order to be able to grip the fragment with the extractor.

A dilemma exists in fragment removal: there is no clear evidence that retained instrument fragments have any impact on prognosis. ${ }^{9}$ Instrument fragment inhibit cleaning and shaping of an infected root canal system. Insufficient mechanical and chemical treatment may have a negative impact on the treatment outcome and reduce the chances of successful treatment. ${ }^{8}$ However, fragment removal procedures weaken the teeth. ${ }^{5}$ In the present study, instrument fracture occurred in the initial stage of the root canal preparation. In both cases the canal could not be sufficiently cleaned and shaped. The fragment was very long and blocked the entire canal system. It was impossible to bypass the broken instrument. As a result it was decided to remove the fragment using the Masserann Kit.

This report showed that the Masserann Kit was successful in the retrieval of tightly wedged fragments from maxillary premolar and molar teeth. However it should be employed with proper case selection. In the hands of a skilled clinician, the Masserann Kit is effective only in the straight portion of the canal is cases with adequate surrounding dentin and straight line accessibility.

In the present study, both cases were diagnosed with chronic apical periodontitis. In general, chronic apical periodontitis treated with multiple-visit root canal treatment. However, in the present both cases treated with single-visit root canal treatment because of the use of proper instrumentation and irrigation procedures, aseptic operating procedures. Also during the root canal filing there was no exudate. Waltimo et al. ${ }^{16}$ report that, when adequate bacterial reduction with $\mathrm{NaOCl}$ irrigation was obtained, there was no significance difference between single or multi-visit treatment of chronic apical periodontitis.

\section{REFERENCES}

1. Gencoglu N, Helvacioglu D. Comparison of the different techniques to remove fractured endodontic instruments from root canal systems. Eur J Dent 2009;3:90-95.

2. Iqbal MK, Kohli MR, Kim JS. A retrospective clinical study of incidence of root canal instrument separation in an endodontics graduate program: a PennEndo database study. J Endod 2006;32:1048-1052.

3. Agrawal V, Kapoor S, Patel M. Ultrasonic technique to retrieve a rotary nickel-titanium file broken beyond the apex and a stainless steel file from the root canal of a mandibular molar: a case report. J Dent (Tehran) 2015;12:532-536.

4. Parashos P, Messer HH. Rotary NiTi instrument fracture and its consequences. $\mathrm{J}$ Endod 2006;32:1031-1043.

5. Gerek M, Baser ED, Kayahan MB, Sunay H, Kaptan RF, Bayirli G. Comparison of the force required to fracture roots vertically after ultrasonic and Masserann removal of broken instruments. Int Endod J 2012;45:429-434.

6. Ward JR, Parashos P, Messer HH. Evaluation of an ultrasonic technique to remove fractured rotary nickel-titanium endodontic instruments from root canals: an experimental study. J Endod 2003;29:756763.

7. Alomairy KH. Evaluating two techniques on removal of fractured rotary nickel-titanium 
endodontic instruments from root canals: an in vitro study. J Endod 2009;35:559-562.

8. Cuje J, Bargholz C, Hulsmann M. The outcome of retained instrument removal in a specialist practice. Int Endod J 2010;43:545554.

9. Panitvisai P, Parunnit P, Sathorn C, Messer $\mathrm{HH}$. Impact of a retained instrument on treatment outcome: a systematic review and meta-analysis. J Endod 2010;36:775-780.

10.Jadhav GR. Endodontic management of a two rooted, three canaled mandibular canine with a fractured instrument. J Conserv Dent 2014;17:192-195.

11.Brito-Junior M, Normanha JA, Camilo CC, Faria-e-Silva AL, Saquy PC, Ferraz MA, et al. Alternative techniques to remove fractured instrument fragments from the apical third of root canals: report of two cases. Braz Dent J 2015;26:79-85.

12. Yoldas O, Oztunc H, Tinaz C, Alparslan N. Perforation risks associated with the use of Masserann endodontic kit drills in mandibular molars. Oral Surg Oral Med Oral Pathol Oral Radiol Endod 2004;97:513-517.

13. Thirumalai AK, Sekar M, Mylswamy S. Retrieval of a separated instrument using Masserann technique. J Conserv Dent 2008;11:42-45.
14. Masserann J. "Entfernen metallischer Fragmente aus Wurzelkanalen" (Removal of metal fragments from the root canal). $\mathrm{J} \mathrm{Br}$ Endod Soc 1971;5:55-59.

15. Shen Y, Peng B, Cheung GS. Factors associated with the removal of fractured NiTi instruments from root canal systems. Oral Surg Oral Med Oral Pathol Oral Radiol Endod 2004;98:605-610.

16. Waltimo $T$, Trope $M$, Haapasalo $M$, Ørstavik D. Clinical efficacy of treatment procedures in endodontic infection control and one year follow-up of periapical healing. J Endod 2005;31:863-6.

\section{Correspondence Author}

Hakan Göktürk

Abant Izzet Baysal University

Faculty of Dentistry

Department of Endodontics

Bolu 14100, Turkey

Phone: +90-374-254 1000 ext-8453

Fax: +90-374-270 0066

E-mail: gokturk82@hotmail.com 